\title{
Job satisfaction, burnout and turnover intention of nurses working in hospital during the pandemic COVID-19 in Turkey
}

\author{
Nukhet Bayer ${ }^{1}$, Zehra Golbasi ${ }^{1}$, Yasin Uzuntarla ${ }^{2}$, Kamile Akarsu ${ }^{3}$ \\ ${ }^{I}$ Nursing Department, Faculty of Health Sciences, Lokman Hekim University, Ankara, Turkey \\ ${ }^{2}$ Department of Health Management, Gülhane Training and Research Hospital, Ankara, Turkey \\ ${ }^{3}$ Surgery of Nursing Department, Health Services Vocational School, Lokman Hekim University, Ankara, Turkey
}

Received: 2021-10-19.

Accepted: 2021-11-07

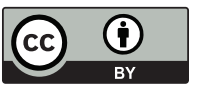

This work is licensed under a Creative Commons Attribution 4.0 International License

\section{J Clin Med Kaz 2021; 18(6):69-75}

Corresponding author:

Yasin Uzuntarla.

E-mail: yasinuzuntarla@gmail.com;

ORCID: 0000-0002-5021-3763

\section{Abstract}

Aim: The turnover intention due to low job satisfaction and burnout and the elimination of the negative effects it causes are of great importance during the pandemic COVID-19 particularly in some countries such as Turkey that public health is concerned, there has been an ongoing effort to improve its background and lack the number of nurses per capita. The aim of this study was to examine the relationship between job satisfaction, burnout, and turnover intention in nurses working in hospitals during the COVID-19 pandemic.

Material and methods: The descriptive research design was applied and conducted in a training and research hospital affiliated to the Ministry of Health in Ankara, Turkey. The subjects consisted of 251 nurses. The data were collected using the Minnesota Satisfaction Questionnaire, the Maslach Burnout Inventory and the Turnover Intention Scale. The Mann-Whitney $U$ test, the Kruskal-Wallis Variance test, and the Structural Equation Modeling were used to analyze the data.

Results: Emotional exhaustion subscale had the greatest effect on turnover intention. An increase in job satisfaction score causes an average decrease on the turnover intention score. The low job satisfaction of the nurses who take care of COVID-19 diagnosed patients has been determined to have negative impact on their turnover intention and burnout.

Conclusion: Job satisfaction, burnout, and turnover intention in nurses were examined and all of these factors were found to be moderate. However, in this study, the job satisfaction of the nurses in caring of patients with COVID-19 infection was lower than that of the nurses who did not.

Key words: job satisfaction, burnout, turnover intention, nurses, COVID-19

\section{Introduction}

COVID-19, a global pandemic has greatly distressed the lives of millions of people since it first appeared in China in 2019. According to the World Health Organization (WHO), since October 2021, a total of 240 million people infected with the disease and nearly 5 million people died worldwide [1]. Nurses, who provide the majority of healthcare services, are also at the forefront of combating pandemic. It has been seen that the pandemic and the fight against it have psychological effects as well as health-related, social, and economic negative effects on people and societies. The stress of the urgent/unexpected delegation to intensive care units and COVID-19 services, the difficulty of working with protective equipment, the high rate of deaths, the risk of getting sick due to the lack of personal protective equipment, and most importantly, the fear of infecting family members have had social and psychological effects on nurses [2]. In a study conducted in 34 hospitals in China, it was found that female nurses who provide frontline care to patients with COVID-19 have high levels of depression, anxiety, insomnia, and distress during this period [3]. During the pandemic COVID-19 in Iran, job satisfaction of the healthcare personnel was examined, and it was found that there was higher depression, anxiety, and lower job satisfaction in healthcare personnel whose COVID-19 test results were not known compared to $69.7 \%$ of the personnel who were reported to have negative COVID-19 test result. It was also found that the staff who had easier access to protective personal equipment had better physical health outcomes and job satisfaction [4]. 
The first detected COVID-19 case in Turkey was announced by the Ministry of Health on March 10, 2020. As of October 2021, a total of 50 thousand people died as a result of COVID-19, while the total number of cases was reported to be 6 million in Turkey [1]. Predictably there has been no research study in this field during the pandemic COVID-19 in Turkey. Even before the pandemic COVID-19, the feeling of burnout, which stood out as an important problem in nurses, has been determined in some studies to be very common among nurses in Turkey as well. It was concluded that as job satisfaction increases, burnout decreases and quality of life increases accordingly [5]. In another study, a strong relationship was found between all elements of burnout and depression, while the depression score was higher in nurses aged thirty years and over with a chronic disease [6].

The feeling of burnout intensely experienced by nurses is defined as energy loss, exhaustion, weakness, and fatigue [7]. Burnout significantly affects institutional performance, patient care quality, patient safety, and as a result, patient health outcomes [8]. In this respect, preventing burnout is critical, because nurses, whose own lives and the lives of their loved ones are at risk, already have high turnover intention and low job satisfaction. Job satisfaction is undoubtedly one of the most important factors that keep them at work [4]. Among the factors affecting job satisfaction are work stress, resilience, perceived organizational support, task-oriented leadership, mobbing, job obligations, insufficient educational opportunities and support, perceived image of the nursing profession, and the sense of discrimination $[9,10]$.

As it is common in the other countries, nursing shortage is a worrying phenomenon affecting the quality of health services in Turkey as well. Compared to the countries of the Organization for Economic Co-operation and Development (OECD), the number of nurses per 100.00 population remains 301 in Turkey. That is why, Turkey has been ranked the last row among 35 OECD countries in terms of the number of nurses per capita [11]. During the COVID-19 admitting the patients to the hospital has been more than its capacity. Since some of the hospitals have become pandemic hospitals and the number of the nurses remained still the same, it can be concluded that the feeling of burnout in the nurses has risen up and job satisfaction has declined. Based on the data, it can be said that the high number of patients per nurse causes an increase in burnout in nurses and a decrease in job satisfaction. Among the factors that increase turnover intention of the nurses, job satisfaction and burnout have a direct effect on turnover intention. Nurses with low job satisfaction have higher turnover intention [12].

The aim of this study was to examine the relationship between job satisfaction, burnout, and turnover intention in nurses working in hospitals during the COVID-19 pandemic.

\section{Material and methods}

The descriptive research was conducted in a training and research hospital affiliated to Ministry of Health in Ankara, Turkey. The data of the study were collected in July and August 2020. The subjects of the study consisted of 476 nurses working at the training and research hospital for at least one year. Nonprobability sampling method has been applied in the study and has been tried to reach the whole subjects. The subjects consist of the nurses who worked at least one year in the same hospital and were volunteer to participate in the study. From among the whole paper forms collected, after excluding 49 forms, which were missed, left blank and filled incompletely/incorrectly, a total of 251 forms included in the study. The participation rate in the survey was $52.7 \%$.

\section{Data collection tool}

The data were collected via a form developed by the researchers about the personal and professional characteristics of the nurses, the Turnover Intention Scale, Maslach Burnout Inventory and Minnesota Satisfaction Questionnaire.

Turnover Intention Scale (TIS): The scale was developed by Mobley, Horner, and Hollingsworth (1978) to measure employees' intention to continue to work or quit by self-evaluation. The scale was adapted to Turkish subjects, its reliability and validity were measured [13]. While Cronbach's alpha value was 0.904 , it was 0.817 in this study. The scale has 5-point Likert-type in three items and there is no subscale. The type of items ranges from "1" strongly disagree to "5" strongly agree. The turnover intention is calculated by dividing the total score by three.

Maslach Burnout Inventory (MBI): The scale was developed by Maslach and Jackson (1981) and has twentytwo 5-point Likert-type items in three subscales, containing options from 'strongly disagree' to 'strongly agree'. The scale measures burnout in three subscales: Emotional exhaustion, depersonalization, and personal accomplishment. It was translated into Turkish by Ergin in 1992 and its validity and reliability study was calculated [14]. The scale contained 22 items and three subscales. From these subscales, the score of emotional exhaustion is calculated by summing up nine items, the depersonalization subscale score is obtained by adding the five items while personal accomplishment is gained by adding the eight items. In this study, the Cronbach's alpha value of the emotional exhaustion subscale was 0.848 , the depersonalization subscale was 0.729 , and the personal accomplishment subscale was 0.716 .

Minnesota Satisfaction Questionnaire (MSQ): The scale was developed by Weiss et al. in 1967. The Turkish adaptation of the scale was performed by Baycan in 1985. The MSQ has twenty 5-point Likert-type items rated from "1" very dissatisfied to " 5 " very satisfied. Minnesota satisfaction questionnaire consists of two scales: intrinsic and extrinsic satisfaction. Intrinsic satisfaction score is obtained by dividing the total number of items by twelve and extrinsic satisfaction score is gained by diving the total number of items by eight. General satisfaction is also measured by dividing the total score of the items by twenty. In the present study, the Cronbach's alpha value of general satisfaction subscale was 0.885 , intrinsic satisfaction subscale was 0.824 and extrinsic satisfaction subscale was 0.785 .

\section{Statistical analysis}

Research analysis was performed using the SPSS (Version 20, Chicago IL, USA) package program. Since the parametric test assumptions were not fulfilled, the Mann Whitney U test was used in paired groups and the Kruskal-Wallis test when there were more than two groups in comparing the similarity of the distributions of MBI, MSQ, and TIS total and subscale scores according to the individual and occupational characteristics of the nurses. In the multiple comparison, Bonferroni Test has been applied. $p<0.05$ was accepted as statistically significant. Structural Equation Modeling (SEM) was used to explain the effect of MSQ on the MBI subscale and the effect of these subscales on TIS.

\section{Ethical Aspect of the Study}

Approval for the study was obtained from Lokman Hekim University Non-Interventional Clinical Research Ethics Committee (Decision number 2020/62 and Code no: 
2020058). Written permission was obtained from the hospital administrations where the study was conducted. The nurses invited to the study were informed about the purpose of the study, and those who gave consent to be volunteers were included in the study. Nurses' credentials were not written on the data collection forms.

\section{Results}

The sociodemographic characteristics of the participants are presented in Table 1. It was observed that $77.69 \%$ of the nurses were women and $22.31 \%$ were men. Their average age was $30.53 \pm 7.69$ years.

Mean MSQ score was $2.85 \pm 0.57$ ( $\min =1 ; \max =4.25)$. MSQ intrinsic satisfaction mean score was measured as $3.00 \pm 0.60$ $(\min =1 ; \max =4.25)$ and extrinsic satisfaction mean score was $2.62 \pm 0.64$ ( $\min =1 ; \max =4.38)$. MBI emotional exhaustion mean score was $29.48 \pm 6.45(\min =13 ; \max =45)$, depersonalization mean score was $11.94 \pm 2.92(\min =5 ; \max =23)$, and personal accomplishment mean score was $28.12 \pm 4.15 \quad$ ( $\min =16$; $\max =37,00)$. TIS mean score was $2.53 \pm 1.05(\min =1 ; \max =5)$ (Table 2).

Table 3 presents the sociodemographic and professional characteristics of the nurses in relation with their average scores from the MSQ, MBI, and TIS. There was a negative linear and very weak correlation between age and the MBI depersonalization score $(\mathrm{r}=-0.143 ; \mathrm{p}=0.023)$. There was a very weak linear positive correlation between age and the TIS score $(\mathrm{r}=0.133 ; \mathrm{p}=0.036)$. There was a statistically significant difference between mean personal accomplishment scores of the group in terms of the status of having children $(p<0.05)$. Personal accomplishment mean score of the nurses with children was statistically higher than that of those with no children. There was statistically significant difference in MSQ total and subscale scores in terms of being a nurse by their own choice $(p<0.05)$. The MSQ total, intrinsic satisfaction, and extrinsic satisfaction mean scores were higher than those of the nurses who were reluctant to became a nurse $(p<0.05)$, but their MBI emotional exhaustion and depersonalization mean scores were lower $(\mathrm{p}<0.05)$. sociodemographic characteristics

\begin{tabular}{lll}
\hline Variables & $\mathrm{n}$ & $\%$ \\
\hline Age & $30.53 \pm 7.69$
\end{tabular}

Sex

$\begin{array}{lll}\text { Female } & 195 & 77.69\end{array}$

Male $\quad 56 \quad 22.31$

Education Status

Vocational Health High School $\quad 35 \quad 13.94$

Associate Degree $31 \quad 12.35$

University Degree $\quad 177 \quad 70.52$

$\begin{array}{lll}\text { Master's Degree } & 8 & 3.19\end{array}$

Marriage Status

Married $\quad 109 \quad 43.43$

Single $\quad 142 \quad 56.57$

Status of having child

$\begin{array}{lll}\text { Yes } & 100 & 39.84\end{array}$

No $\quad 151 \quad 60.16$

Became a nurse by choice

$\begin{array}{lll}\text { Yes } & 169 & 67.33\end{array}$

$\begin{array}{lll}\text { No } & 82 & 32.67\end{array}$

The number of years as a nurse $\quad 7.46 \pm 7.89$

The number of years at the current $\quad 5.29 \pm 6.65$ institution

The number of years at the current unit $\quad 2.50 \pm 2.63$

Position

Nurse-in-charge $\quad 14 \quad 5.58$

Department Nurse $\quad 230 \quad 91.63$

Supervisor Nurse $\quad 4 \quad 1.59$

$\begin{array}{lll}\text { Other } & 3 & 1.20\end{array}$

Working in the current unit by choice?

$\begin{array}{lll}\text { Yes } & 178 & 70.92\end{array}$

$\begin{array}{lll}\text { No } & 73 & 29.08\end{array}$

Type of Shift

$\begin{array}{lll}\text { Always Day Shift } & 39 & 15.54 \\ \text { Always Night Shift } & 9 & 3.59 \\ \text { Shifting (Night+Day) } & 203 & 80.88\end{array}$

The Status of Providing Services for

Covid-19 Patients in the Unit

$\begin{array}{lll}\text { Yes } & 203 & 80.88\end{array}$

MSQ, MBI and TIS mean scores of the nurses

\begin{tabular}{|c|c|c|c|c|c|}
\hline Scale: & & Mean & Standard Deviation & Minimum & Maximum \\
\hline MSQ & & 2.85 & 0.57 & 1.00 & 4.25 \\
\hline & Internal Satisfaction & 3.00 & 0.60 & 1.00 & 4.25 \\
\hline & External Satisfaction & 2.62 & 0.64 & 1.00 & 4.38 \\
\hline \multicolumn{6}{|l|}{ MBI } \\
\hline & Emotional Exhaustion & 29.48 & 6.45 & 13.00 & 45.00 \\
\hline & Depersonalization & 11.94 & 2.92 & 5.00 & 23.00 \\
\hline & $\begin{array}{l}\text { Reduced Personal } \\
\text { Accomplishment }\end{array}$ & 28.12 & 4.15 & 16.00 & 37.00 \\
\hline TIS & & 2.53 & 1.05 & 1.00 & 5.00 \\
\hline
\end{tabular}

MSQ: Minnesota Satisfaction Questionnaire, MBI: Maslach Burnout Inventory, TIS: Turnover Intention Scale

Mean TIS scores of the nurses who became a nurse by their own choice were lower than those who were reluctant to became a nurse. A directional very weak relationship was observed between the duration of working life as a nurse and depersonalization score $(\mathrm{r}=-0.162 ; \mathrm{p}=0.010)$. There was a weak directional relationship between the duration of working life as a nurse and personal accomplishment and TIS scores $(\mathrm{r}=0.133$; $\mathrm{r}=0.128$, respectively, $\mathrm{p}<0.05)$. There were statistically significant differences between working in the unit by their own choice and MSQ, extrinsic satisfaction, emotional exhaustion, and TIS means scores $(p<0,05)$. MSQ total and extrinsic satisfaction scores of the nurses working in their units by their own choice were higher than those were reluctant to work in their units $(p<0.05)$. Emotional exhaustion and TIS mean scores of the 


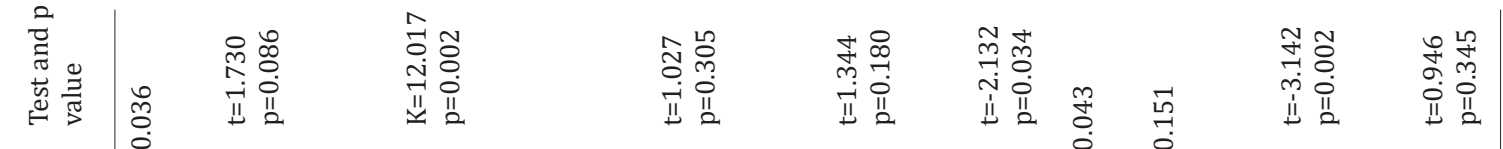

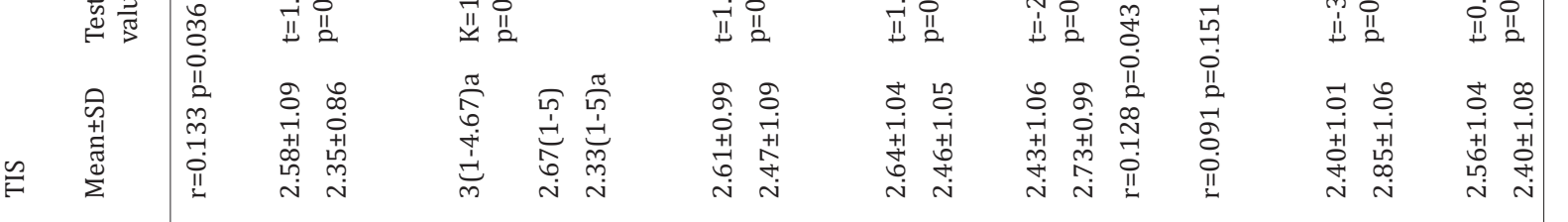

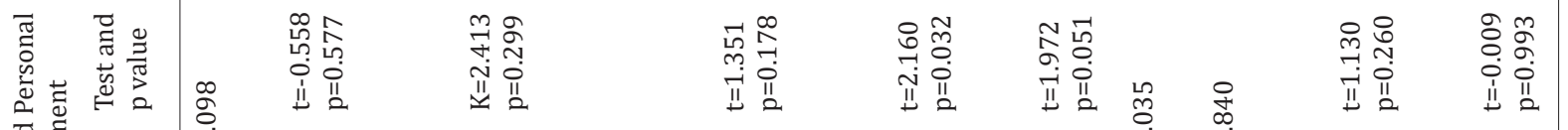

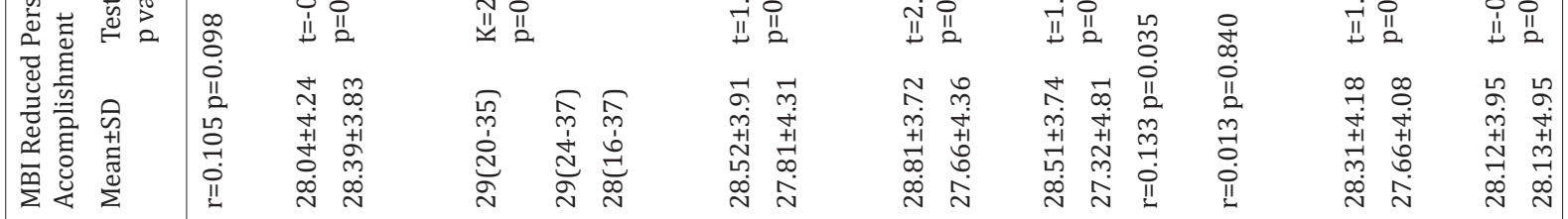

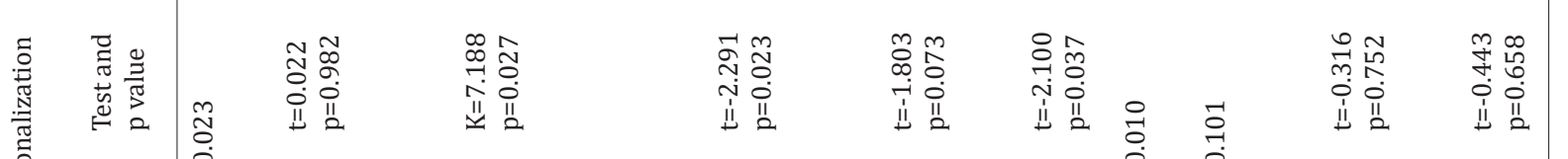

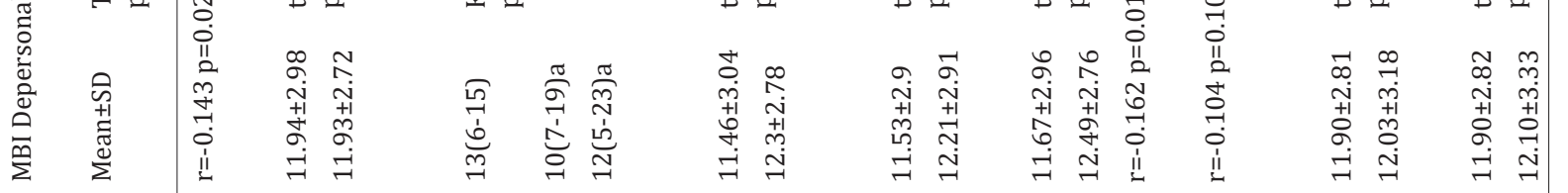

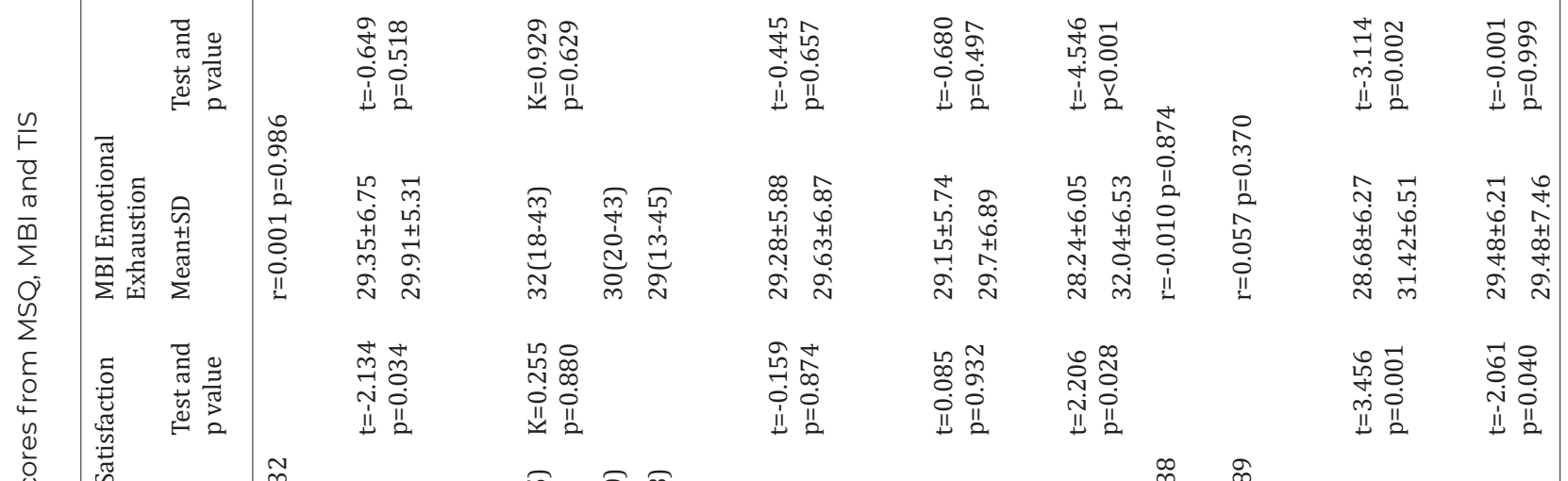

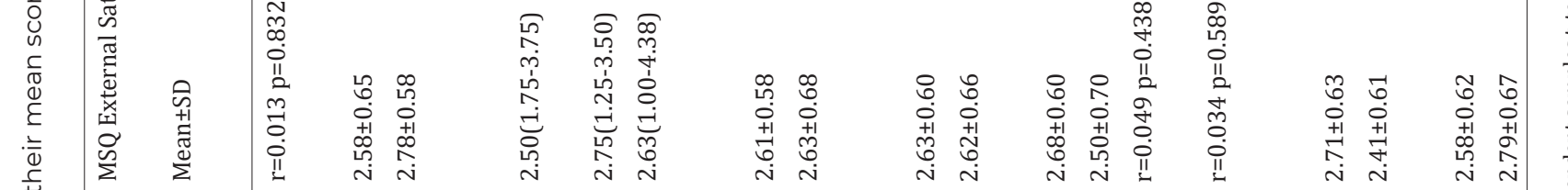

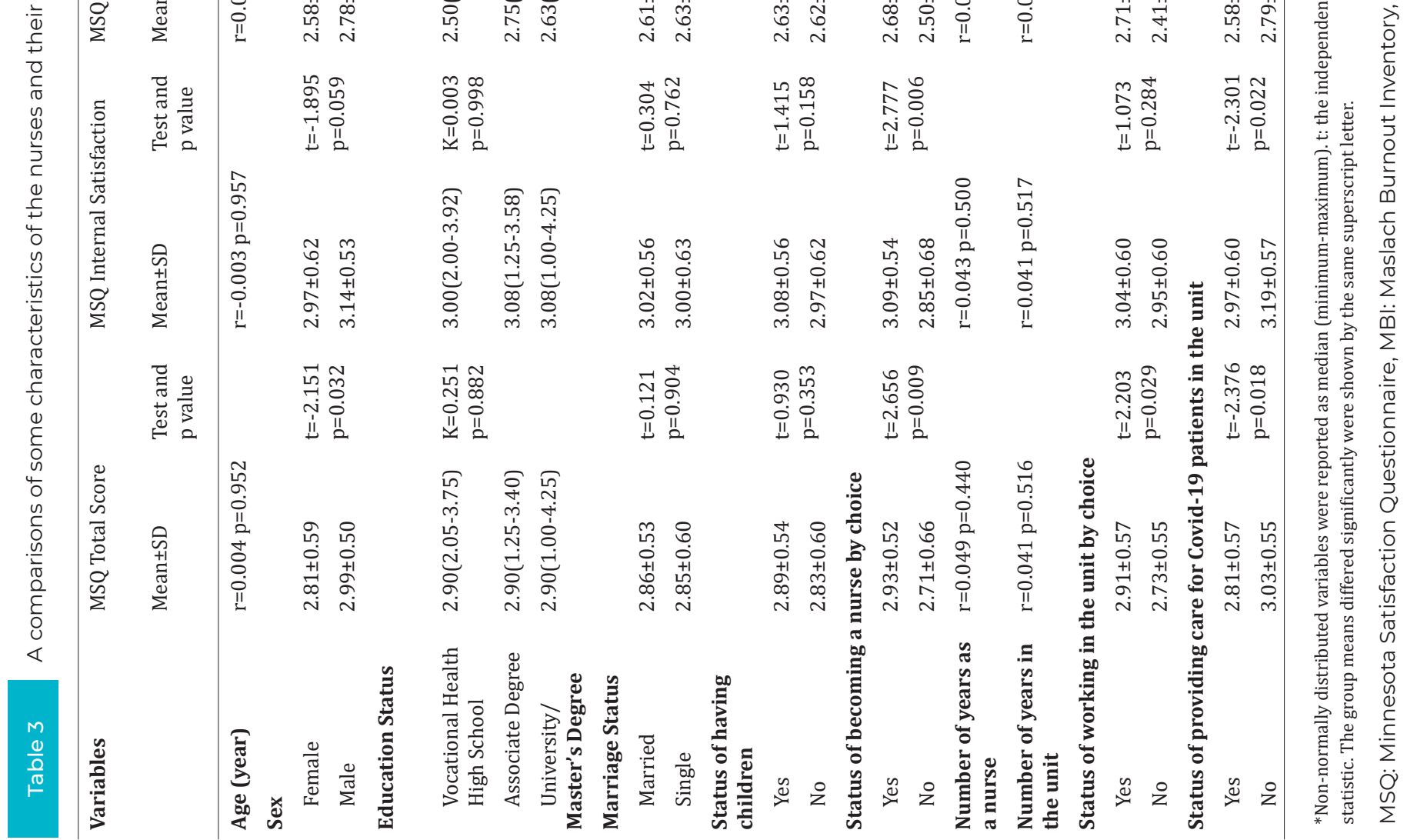




\begin{tabular}{|c|c|c|c|c|c|c|c|}
\hline Dependent Variables & & $\begin{array}{l}\text { Independent } \\
\text { Variables }\end{array}$ & Coefficient & Standard Error & $\begin{array}{l}\text { Standardized } \\
\text { Coefficient }\end{array}$ & t Value & (p) \\
\hline Emotion Exhaustion & $<---$ & $\begin{array}{l}\text { Minnesota } \\
\text { Satisfaction }\end{array}$ & -6.364 & 0.588 & -0.565 & -10.824 & $<0.001$ \\
\hline Depersonalization & $<---$ & $\begin{array}{l}\text { Minnesota } \\
\text { Satisfaction }\end{array}$ & -1.333 & 0.311 & -0.261 & -4.283 & $<0.001$ \\
\hline $\begin{array}{l}\text { Personal } \\
\text { Accomplishment }\end{array}$ & $<---$ & $\begin{array}{l}\text { Minnesota } \\
\text { Satisfaction }\end{array}$ & 2.236 & 0.436 & 0.308 & 5.128 & $<0.001$ \\
\hline Turnover & $<---$ & $\begin{array}{l}\text { Reduced Personal } \\
\text { Accomplishment }\end{array}$ & -0.054 & 0.014 & -0.212 & -3.914 & $<0.001$ \\
\hline Turnover & $<---$ & $\begin{array}{l}\text { Minnesota } \\
\text { Satisfaction }\end{array}$ & -0.269 & 0.119 & -0.146 & -2.258 & 0.024 \\
\hline Turnover & $<---$ & Depersonalization & -0.031 & 0.020 & -0.085 & -1.505 & 0.132 \\
\hline Turnover & $<--$ & $\begin{array}{l}\text { Emotional } \\
\text { Exhaustion }\end{array}$ & 0.069 & 0.011 & 0.424 & 6.432 & $<0.001$ \\
\hline
\end{tabular}

Figure 1 - Structural Equation Model for the nurses' job satisfaction, burnout, and turnover intention levels

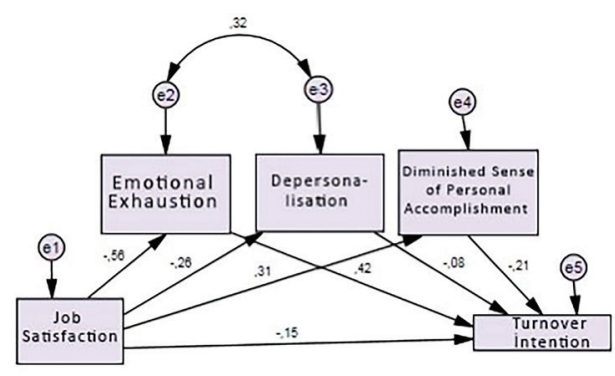

nurses working in their unit by their own choice were lower than those TIS scores of the nurses who became a nurse by their own choice were lower than those who were reluctant to work in their unit $(\mathrm{p}<0.05)$. MSQ total, intrinsic satisfaction, and extrinsic satisfaction mean scores of those providing healthcare services to COVID-19 patients in their units were lower than those who did not $(p<0.05)$. No difference was observed between MBI and TIS in terms of the nurses' status of providing healthcare services to COVID-19 patients in their units ( $p>0.05$ ).

Structural Equation Modelling (SEM) was used to examine the relationship between the nurses' job satisfaction, burnout, and turnover intention levels. Figure 1 presents the SEM design. When the fit index values of the structural model established are examined, it is observed that the model has acceptable fit values.

Table 4 presents the estimation results regarding the structural model. The model explains $32.3 \%$ of the turnover intention. When the results are evaluated, depersonalization subscale does not affect turnover intention $(p>0.05)$. The emotional exhaustion subscale $(\beta=0.424)$ has the greatest effect on turnover intention $(\mathrm{p}<0.05)$.

\section{Discussion}

In this study, which was conducted to examine the relationship between job satisfaction, burnout, and turnover intention of the nurses working in the hospital during the COVID-19 pandemic, it was observed that the nurses experienced burnout, emotional exhaustion, depersonalization, and a decrease in personal accomplishment, and half of them had turnover intention. It was found that the general job satisfaction as well as intrinsic and extrinsic satisfaction levels of the nurses were nearly the average. Some studies conducted before the COVID-19 pandemic have shown that nurses' job satisfaction levels were even at low $[15,16]$ or medium level [17-20]. In our study, however the average score of job satisfaction, intrinsic and extrinsic satisfaction subscale of the nurses who are caring for patients with COVID-19 has been determined to have scored lower, compared to those who are not. In a similar way, as it has been detected in our study, Savitsky et al., [21] in a study in Israel have been found that the level of job satisfaction of the nurses who take care of patients with COVID-19 was lower than that of the other nurses. The reason for these results can be associated with the tough conditions at the advent of the pandemic disease.

In our study, it was found that nurses experienced burnout. Emotional exhaustion and depersonalization were nearly medium, and personal accomplishment was rather high. However, a high level of professional burnout among nurses before the pandemic in Turkey were revealed in some studies $[15,22,23]$. In addition, many studies all around the world have found that nurses experience moderate to high levels of burnout [24-28]. In India, burnout levels among healthcare personnel were examined during the COVID-19 pandemic, and more than half of the participants $(52.8 \%)$ had high level of burnout due to the pandemic [29].

Nurses' low job satisfaction and high burnout levels are among the reasons for their turnover intention, which is a global problem all over the world $[9,30]$. In some pre-pandemic studies, it was found that more than half of the nurses participating in the study had high turnover intention [5, 31]. In our study, turnover intention scale mean score of the nurses was moderate. Despite the increased workload, stress, and anxiety during the pandemic, the fact that nurses' turnover levels remained at a moderate level, the turnover intention of the nurses can be prevented in case the government pays additional wages to the nurses during the COVID-19 pandemic. In a study, it was found that $45 \%$ of nurses were not satisfied with their current job because of their salaries [32]. In Philippine, in a research study during the COVID-19 pandemic, the job satisfaction of the nurses had decreased due to their fear of infection. At the same time, the turnover intention of the nurses had risen up both organizationally and professionally [33].

Job satisfaction of nurses has significantly affected their turnover intention. This outcome becomes even more important in countries, such as Turkey, where there are a relatively low number of nurses per capita. When the results of the Structural Equation Model are examined in our study, the model estimates the $32.3 \%$ of the turnover intention. Emotional exhaustion subscale $(\beta=0.424)$ has the greatest effect on turnover intention. One unit increase in the nurses' job satisfaction score causes an average of 0.013 units of decrease on the turnover intention scale score. In a study comparing nurses' burnout and job 
satisfaction levels, it was found that each subscale had a statistically significant relationship with each other [34]. It has been found that there has been a negative relationship between depersonalization subscale and turnover intention of the nurses. This can be interpreted as high depersonalization that can causes low turnover intention. Besides, job satisfaction of the nurses causes positive consequences in terms of organizational and professional performance. The high level of job satisfaction of the nurses has an impulsive impact on their intention to keep at work.

While some studies found a positive relationship between job satisfaction and nurses' low intention to keep them at work $[35,36]$, a negative relationship was found between emotional exhaustion and depersonalization and their intention to continue to work. Higher emotional exhaustion and depersonalization plays an important role in turnover intention of the nurses. Accordingly, an increase in emotional exhaustion and depersonalization causes an increase in turnover intention. Furthermore, job satisfaction in nurses has positive results on both organizational and professional levels. Job satisfaction is a very effective driving force in keeping nurses at work. Organization-based self-esteem, social support, and job satisfaction have a mediating effect on nurses' low turnover intention [37]. The mediating effect of job satisfaction in the relationship between professional identity and turnover among nurses was investigated and it was determined that job satisfaction had a full mediating effect on the impact of professional identity on turnover intention [38]. Job satisfaction and emotional/normative professional commitment have positive effect on nurses' low turnover intention [5, 39]. It was found that perceived organizational support, job control, and job satisfaction had positive predictive effects on low turnover intention, and also, job satisfaction and job control had a mediating effect on the model of intention to continue [40].

The research results are limited to the hospital where the research was conducted. One of the most significant limitations of the study is the low rate of participation that is $52.7 \%$.

\section{Conclusion}

As a result, job satisfaction, burnout and turnover intention of the nurses were at medium level. When the fit index values of the established structural model are examined, it is observed that the model has acceptable fit values. The emotional exhaustion subscale of the MBI has the greatest effect on turnover intention scale. The hospital management and decision makers should reduce the turnover intention of nurses by creating working conditions that will increase the job satisfaction and reduce their burnout, especially during the COVID-19 pandemic.

Disclosures: There is no conflict of interest for all authors.

Acknowledgements: We would like to thank all nurses for participating in this study.

Funding: None.

\section{References}

1. WHO. World Health Organization Coronavirus (COVID-19) dashboard 2021 [Available from: https://covid19.who. int/?gclid=Cj0KCQjw6-SDBhCMARIsAGbI7Ug8NzsdYJjUkfGwTkwOe5ONLdhB53CxY4vrK72ShR327KgZ7zYzj5caAq96EA Lw_wcB. / Accessed; October 17, 2021.

2. Cabrera MA, Karamsetty L, Simpson SA. Coronavirus and its implications for psychiatry: A rapid review of the early literature. Psychosomatics. 2020;61(6):607-15. doi: 10.1016/j.psym.2020.05.018

3. Lai CC, Shih TP, Ko WC, Tang HJ, Hsueh PR. Severe acute respiratory syndrome coronavirus 2 (SARS-CoV-2) and coronavirus disease-2019 (COVID-19): The epidemic and the challenges. Int J Antimicrob Agents. 2020;55(3):105924. doi: 10.1016/j. ijantimicag.2020.105924

4. Zhang SX, Liu J, Afshar Jahanshahi A, Nawaser K, Yousefi A, Li J, et al. At the height of the storm: Healthcare staff's health conditions and job satisfaction and their associated predictors during the epidemic peak of COVID-19. Brain Behav. Immun. 2020;87:144-6. doi: 10.1016/j.bbi.2020.05.010

5. Çelik M, Yıldız B. Occupational commitment, identification and intention to leave of nurses: Public Sector and private sector comparison. Kastamonu Üniversitesi Íktisadi ve İdari Bilimler Fakültesi Dergisi. 2018;20(2):47-57. doi:iibfdkastamonu.343309

6. Bakir B, Ozer M, Ozcan CT, Cetin M, Fedai T. The Association between burnout, and depressive symptoms in a Turkish military nurse sample. Bulletin of Clinical Psychopharmacology. 2010;20:160-3.doi: 10.1080/10177833.2010.11790651

7. Leiter MP, Maslach C. Latent burnout profiles: A new approach to understanding the burnout experience. Burn. Res. 2016;3(4):89-100. doi:10.1016/j.burn.2016.09.001

8. Ross J. The exacerbation of burnout during COVID-19: A major concern for nurse safety. J Perianesth Nurs. 2020;35(4):439-40. doi: 10.1016/j.jopan.2020.04.001

9. Lo W-Y, Chien L-Y, Hwang F-M, Huang N, Chiou S-T. From job stress to intention to leave among hospital nurses: A structural equation modelling approach. J. Adv. Nurs. 2018;74(3):677-88. doi: 10.1111/jan.13481

10. Gillet N, Fouquereau E, Coillot H, Bonnetain F, Dupont S, Moret L, et al. Ethical leadership, professional caregivers' well-being, and patients' perceptions of quality of care in oncology. Eur J Oncol Nurs. 2018;33:1-7. doi: 10.1016/j.ejon.2018.01.002

11. HSY. Health Statistics Yearbook The Ministry of Health of Turkey Health Statistics Yearbook 2018. [Available from: https://dosyasb. saglik.gov.tr/Eklenti/36164,siy2018en2pdf.pdf?0. / Accessed; September 17, 2021.

12. Chan ZCY, Tam WS, Lung MKY, Wong WY, Chau CW. A systematic literature review of nurse shortage and the intention to leave. $J$. Nurs. Manag.2013;21(4):605-13. doi: 10.1111/j.1365-2834.2012.01437.x.

13. Örücü E, Özafşarlioğlu S. The influence of organizational justice on the turnover intention: A study in the Republic of South Africa. Mustafa Kemal University Journal of Social Sciences Institute. 2013;10 (23):335-58.

14. Ergin C. Doktor ve Hemşirelerde Tükenmişlik ve Maslach Tükenmişlik Ölçeğin Uyarlanması. VII Ulusal Psikoloji Kongresi Bilimsel Çalışmaları El Kitabı. 1992:143-54.

15. Uzun LN, Mayda AS. Investigation of burnout levels in nurses according to different variables: Example of a universty hospital. Konuralp Med J. 2020;12(1):137-43. doi: 0.18521/ktd.493186 
16. Kaçan CY, Örsal Ö, Köşgeroğlu N. Determination of job satisfaction levels among nurses. Hemşirelikte Araştırma Geliştirme Dergisi. 2016;18(2-3):1-12.

17. Kelleci M, Gölbaşı Z, Doğan S, Ata EE, Koçak E. The relationship of job satisfaction and burnout level with quality of life in hospital nurses. Cumhuriyet Medical Journal. 2011;33:144-52.

18. Çelik Y, Kiliç İ. The relationships between job satisfaction, professional burnout and quality of life in nurses. Kocatepe Medical Journal. 2019;20:230-8. doi: 10.18229/kocatepetip.444706

19. Aytekin A, Yilmaz Kurt F. Factors affecting the job satisfaction of nurses working in the neonatal intensive care unit. Journal of Dr Behcet Uz Children's Hospital. 2014;4(1):51-8. doi: 10.5222/buchd.2014.051

20. Aksoy NM. Job satisfaction and affecting factors of surgical unit nurses of 3 different hospitals in a province in mediterranean region. Journal of Education and Research in Nursing. 2013;10(2):45-53.

21. Savitsky B, Radomislensky I, Hendel T. Nurses' occupational satisfaction during Covid-19 pandemic. Appl Nurs Res. 2021;59:151416. doi: 10.1016/j.apnr.2021.151416

22. Kebapci A, Akyolcu N. The effects of the work environment on nurse burnout in emergency department. Turk. J. Emerg. Med. 2011;11(2):59-67. doi: 10.5505/1304.7361.2011.43827

23. Özmen Z. An investigation into the burnout levels of nurses by means of maslach burnout inventory: A sample from Bursa Sevket Yilmaz education and research hospital nurses. Istanbul: T.C. Beykent Üniversitesi; 2016.

24. Lasebikan VO, Oyetunde MO. Burnout among nurses in a Nigerian General Hospital: Prevalence and associated factors. International Scholarly Research Network ISRN Nurs. 2012;2012:402157. doi: 10.5402/2012/402157

25. Kelly LA, Gee PM, Butler RJ. Impact of nurse burnout on organizational and position turnover. Nurs Outlook. 2021;69(1):96-102. doi: 10.1016/j.outlook.2020.06.008

26. Rudman A, Arborelius L, Dahlgren A, Finnes A, Gustavsson P. Consequences of early career nurse burnout: A prospective longterm follow-up on cognitive functions, depressive symptoms, and insomnia. EClinicalMedicine. 2020;27:100565. doi: 10.1016/j. eclinm.2020.100565

27. Woo T, Ho R, Tang A, Tam W. Global prevalence of burnout symptoms among nurses: A systematic review and meta-analysis. $J$. Psychiatr. Res. 2020;123:9-20. doi: 10.1016/j.jpsychires.2019.12.015

28. Janeway D. The Role of psychiatry in treating burnout among nurses during the Covid-19 pandemic. J Radiol Nurs. 2020;39(3):176-8. doi: 10.1016/j.jradnu.2020.06.004

29. Khasne RW, Dhakulkar BS, Mahajan HC, Kulkarni AP. Burnout among healthcare workers during COVID-19 Pandemic in India: Results of a questionnaire-based survey. Indian J Crit Care Med. 2020;24(8):664-71. doi: 10.5005/jp-journals-10071-23518

30. Roelen CA, Mageroy N, van Rhenen W, Groothoff JW, van der Klink JJ, Pallesen S, et al. Low job satisfaction does not identify nurses at risk of future sickness absence: results from a Norwegian cohort study. Int. J. Nurs. Stud. 2013;50(3):366-73. doi: 10.1016/j. ijnurstu.2012.09.012

31. Haydari SM, Kocaman G, Tokat MA. A survey on the intention of the nurses' of different generations to leave their job and profession and their organizational and professional commitment. Journal of Health and Nursing Management. 2016;3(3):119-31. doi:10.5222/ SHYD.2016.119

32. Zhang L-F, You L-M, Liu K, Zheng J, Fang J-B, Lu M-M, et al. The association of Chinese hospital work environment with nurse burnout, job satisfaction, and intention to leave. Nurs Outlook. 2014;62(2):128-37. doi: 10.1016/j.outlook.2013.10.010

33. Labrague, LJ, de los Santos, J. Fear of COVID-19, psychological distress, work satisfaction and turnover intention among frontline nurses. J Nurs Manag. 2021; 29: 395- 403. doi: 10.1111/jonm.13168

34. Torun T, Çavuşoğlu H. Examining burnout and job satisfaction of nurses working in pediatric units. Journal of Education and Research in Nursing. 2018;15(2):71-80. doi: 10.5222/HEAD.2018.071

35. Al-Hamdan Z, Manojlovich M, Tanima B. Jordanian nursing work environments, intent to stay, and job satisfaction. J. Nurs. Scholarsh. 2017;49(1):103-10. doi: 10.1111/jnu.12265

36. Koy V, Yunibhand J, Angsuroch Y, Fisher M. Relationship between nursing care quality, nurse staffing, nurse job satisfaction, nurse practice environment, and burnout: Literature review. Int J Res Med Sci. 2015:1825-31.doi:10.18203/2320-6012.ijrms20150288

37. Chen M-F, Ho C-H, Lin C-F, Chung M-H, Chao W-C, Chou H-L, et al. Organisation-based self-esteem mediates the effects of social support and job satisfaction on intention to stay in nurses. J. Nurs. Manag. 2016;24(1):88-96. doi: 10.1111/jonm.12276.

38. Zhang B, Xiong S-C, Jiang H-B, Qiu Z-Y. Mediating effect of job satisfaction between professional identity and turnover intention in nurses. Chin. J. Clin. Psychol. 2016;24 (6):1123- 5. doi:10.1371/journal.pone.0258387

39. Satoh M, Watanabe I, Asakura K. Occupational commitment and job satisfaction mediate effort-reward imbalance and the intention to continue nursing. Jpn J Nurs Sci. 2017;14(1):49-60. doi: 10.1111/jjns.12135

40. Li X, Zhang Y, Yan D, Wen F, Zhang Y. Nurses' intention to stay: The impact of perceived organizational support, job control and job satisfaction. J. Adv. Nurs. 2020;76(5):1141-50. doi: 10.1111/jan.14305 